\title{
Optimization of compression moulding temperature for polypropylene materials
}

\begin{abstract}
In this work, the effect of processing temperature of polypropylene (PP) on the viscosity and the melt flow index (MFI) is studied towards the best fabrication of PP/kenaf composites. PP with MFI grade 41 and as density value of $0.95 \mathrm{~g} / \mathrm{cm} 3$ is used as a raw material. The compression moulding machine is utilized to produce the moulded samples from PP pallets. The viscosity and the MFI tests have been selected as criteria to determine an optimum processing temperature. As optimum temperature $230^{\circ} \mathrm{C}$ has been found.
\end{abstract}

Keyword: Polypropylene; Moulding machines; Moulding temperature; Processing temperature 